\title{
Radio Astronomy in Turkey: Site selection studies for radio quiet zones
}

\author{
İbrahim Küçük* \\ Erciyes University, Science Faculty, Dept. Astronomy and Space Sciences, 38039, Kayseri, \\ TURKEY \\ E-mail: kucuk@erciyes.edu.tr
}

Site selection studies for a $40 \mathrm{~m}$ single-dish Radio Telescope in Turkey were started as a State Planning Organization Project by "Turkey's National Radio Astronomy Observatory Site Selection Committee". The project began on 04 May 2007 and was completed on 31 December 2008. Within this project, meteorological and atmospheric atlases, topographical \& earthquake analysis, and Radio Frequency (RF) spectrum measurements were compiled for the whole of Turkey, and then used to analyze and compare potential stations. In this paper, the analysis of spectral measurements, determination of the radio quiet zone and atmospheric, meteorological and topographic studies of new measurement stations are given. This project was executed in cooperation with the Agency of Information \& Communication Technologies (BTK), General Directorate of State Meteorology Affairs (DMGM), General Directorate of TÜB İTAK - Space, General Directorate of Disaster Affairs, General Directorate of Mineral Research \& Exploration (MTA), General Command of the Map, and Erciyes University of Turkey. The National Radio Astronomy site selection studies have been completed in cooperation with all of these institutions for the first time.

RFI mitigation workshop

29-31 March 2010

Groningen, the Netherlands

\footnotetext{
${ }^{*}$ Speaker.
} 


\section{National Radio Astronomy Observatory}

One of the important activities in the technology foresight project of Turkey for 'vision 2023' is the establishment of a national radio astronomy observatory to have a 30-40 m dish antenna. Educational studies have started in Erciyes University for this purpose. A $13 \mathrm{~m}$ radio telescope with a $22 \mathrm{~m}$ diameter radome and two $5 \mathrm{~m}$ radio antennas have been built.

\section{Previous Attempts}

\subsection{Between 1990-1995}

The efforts to build a radio telescope in Turkey started first between 1990-1995, with a 2 $m$ radio telescope project, which was nationally funded by TÜB İTAK Marmara Research Center (MRC). The design considerations were jointly for radio astronomical observations and for remote sensing image reception. This telescope was built to work between $85-115 \mathrm{GHz}$ for CO observations of the Milky Way.

\subsection{Between 2000-2005}

Radio Astronomy is considered to be one of the main research areas in several astronomy and physics departments. Among them, Erciyes University, in Kayseri, which has built two $5 \mathrm{~m}$ antennas and a $13 \mathrm{~m}$ antenna with a radome: educational radio astronomy was started.

\section{Current Situation and Site Selection Studies}

Two State Planning Organization (DPT) projects were carried out to establish a national radio astronomy observatory. Site selection studies started in 2008. Analysis has been made in two parts under the headings atmospheric-meteorological, and radio quiet zone. The first steps in the procedure are:

- determination and calculation of required meteorological and atmospheric parameters for the radio observatory [4], [5],

- the historical development of the algorithms used in the analysis,

- creation of the required database for the analysis,

- provide information about analysis methods and tools,

- spatial and temporal review of the meteorological and atmospheric parameters

- preparation of a common selection environment.

In the second step, the procedures:

- examination of radio interference effects for a Radio Astronomy Observatory,

- determination of the methods to be used in the spectral measurements [3],

- analysis of measurement instruments,

- evaluation of measurement results 
Table 1: Coordinates and elevations for measurement locations

\begin{tabular}{|l|l|r|r|r|}
\hline CITY & PLACE & $\mathrm{Y}_{D D}$ & $\mathrm{X}_{D D}$ & $\mathrm{Z}_{M}$ \\
\hline Antalya & Elmal1-Korkuteli & 36,9947 & 30,1556 & 1142 \\
\hline Antalya & Akçay Ahatlı Köyü & 36,6058 & 30,2950 & 1118 \\
\hline Antalya & Bozova & 37,2353 & 30,1556 & 868 \\
\hline Burdur & Yeşilova & 37,5689 & 29,8383 & 1169 \\
\hline Karaman & Merkez & 37,1869 & 33,2192 & 1030 \\
\hline Karaman & Yazılı & 37,1375 & 33,0936 & 1065 \\
\hline Karaman & Akçaşehir & 37,4039 & 33,4936 & 1108 \\
\hline
\end{tabular}

\section{Measurements and Interpretations}

We first identified the Burdur, Antalya and Karaman regions for electromagnetic spectrum measurements, as displayed in Figure 1. The Antalya and Burdur regions were both selected to provide atmospheric and meteorological parameters from high mountain zones and for being close to TÜBİTAK National Observatory. Karaman is the region with the lowest seismic risk, taking into account the earthquake zone activity of Turkey. Some examples of the prevailing electromagnetic spectrum are given in Figures 3 - 5 for seven locations identified in these three provinces. Coordinates and elevation information taken with GPS are given in Table 1. Frequency measurements for the range of 0 to 270 degrees polarizations were taken for the horizontal and vertical polarizations using the HL-50 log-periodic antenna [6]. Horizontal and vertical polarizations are provided with park mounting by polarization apparatus that is fitted to a special mast (raising mechanism). Measurements are made over the frequency ranges (span) and bandwidths (RBW) given in Figures 2-6. Reference levels were taken as $-22 \mathrm{dBm}$. Measurements were performed over the spectrum ranges $10 \mathrm{MHz}-1 \mathrm{GHz}, 1-2 \mathrm{GHz}, 2-3 \mathrm{GHz}$, and so on up to $30 \mathrm{GHz}$ with the Omni and HL-50 log-periodic antennas. Identified signal peaks from the frequency scans were examined by increasing the frequency resolution and attempts then made to identify the sources of these transmissions. Interference effects observed during these measurements and their peak frequencies (GSM, TV broadcast, radar, etc.) are captured on the figures. Frequency measurements for the range of 0 to 270 degrees polarizations were taken for the horizontal and vertical polarizations and the HL50 log-periodic antenna is used [6]. Horizontal and vertical polarizations are provided with park mounting by polarization apparatus that is fitted to a special mast (uprising mechanism). Measurements are made in the frequency range (span) and the bandwidth (RBW) given in Figures 2-6. References were taken as $-22 \mathrm{dBm}$. Identified peaks during the frequency scanning were examined by diminish to frequency ranges and were tried to find these transmission sources. Interference effects determined during these measurements and frequency peaks (GSM, TV broadcast, radar, etc.) were captured on the figures. 


\section{References}

[1] J. Cohen, T. Spoelstra, R. Ambrosini, W. van Driel, CRAF Handbook of Radio Astronomy, Third Edition, 2005

[2] Recommendation $I T U-R R A .769-2$, Protection criteria used for radio astronomical measurement, 1992-1995-2003.

[3] R. Ambrosini, RFI selection criteria for new radio telescopes, 17th International Wroclaw Symposium and Exhibition On Electromagnetic Compatibility, Wroclaw, June 29-July 12004.

[4] J. E. Simon et al., Atmospheric Conditions at a Site for Submilimeter Wavelength Astronomy, NRAO.

[5] M. A. McHenry, K. Steadman, Spectrum Occupancy Measurements Location 5 of 6, NRAO, October 10-11 2004, Revision 3.

[6] C. Munoz-Tunon et al., Instrument and Tools for Site Testing, GW3-ESO-Site Evaluation, February 2006.

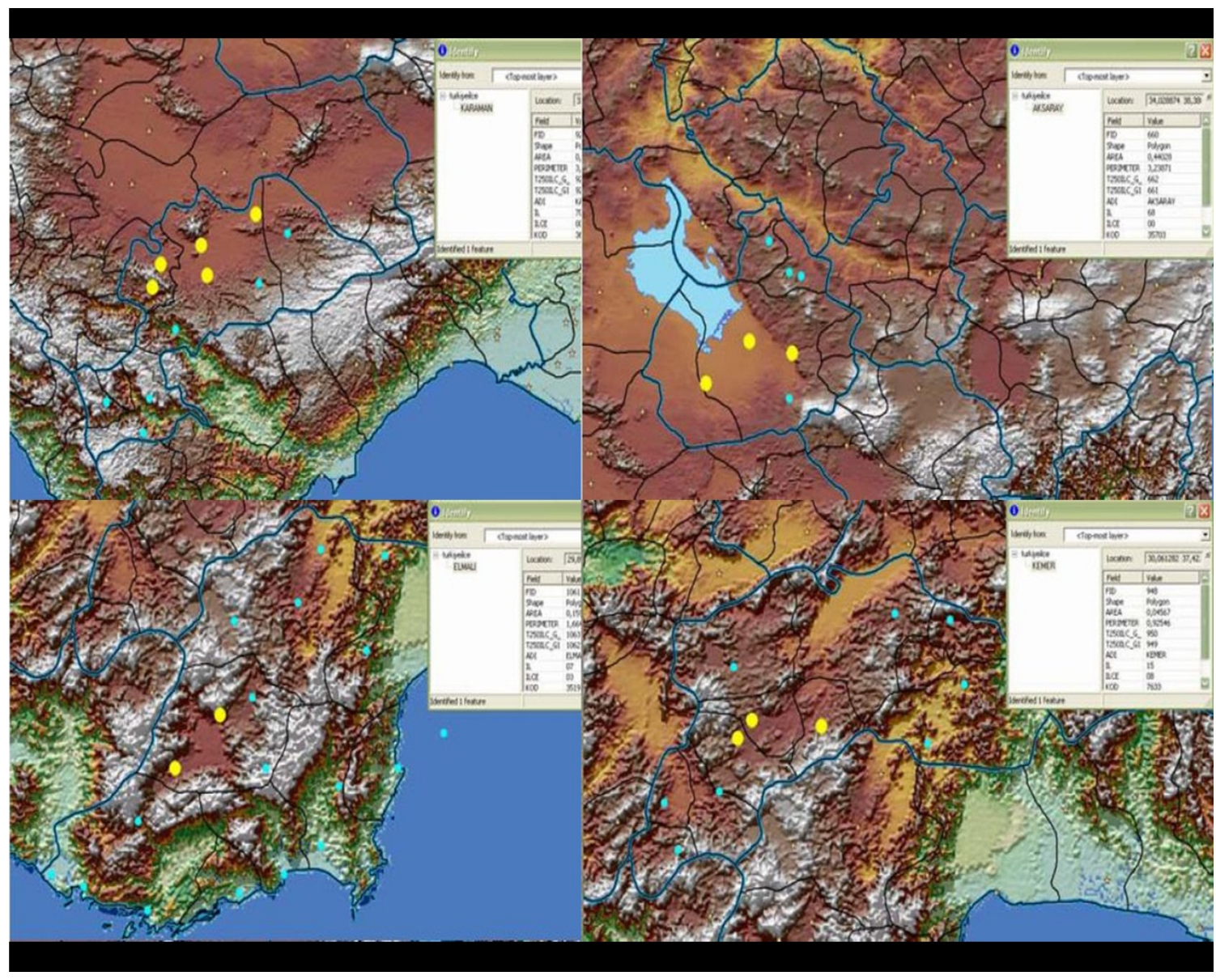

Figure 1: Measurement centers (big open circles) for possible radio quiet zones. 


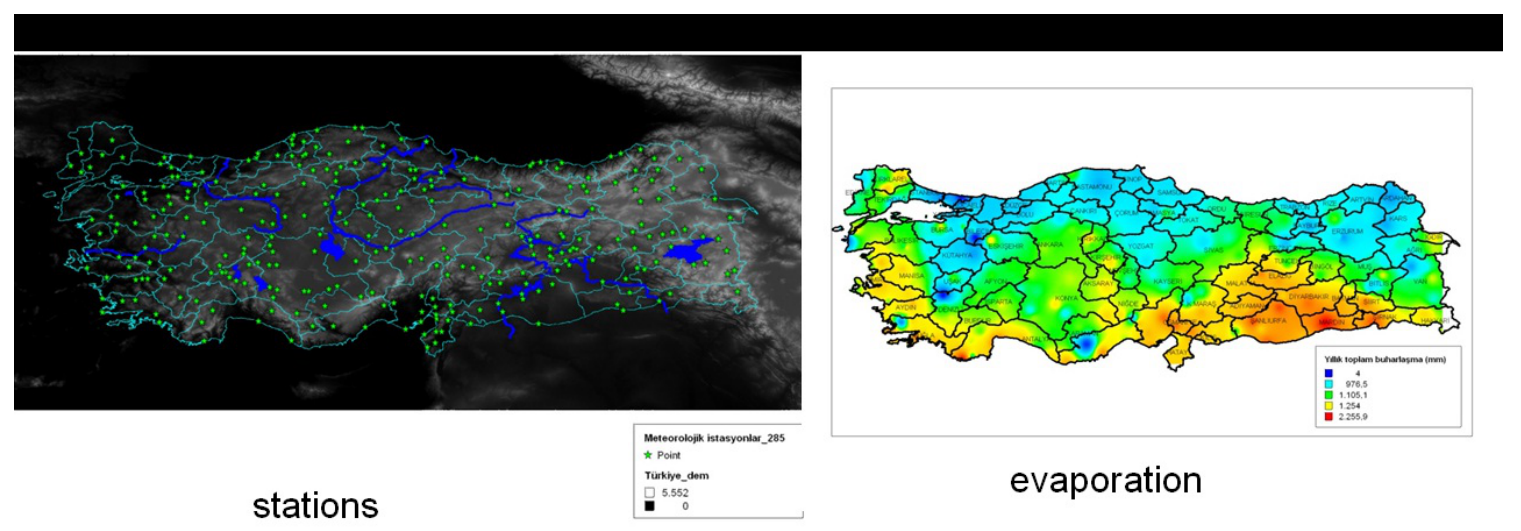

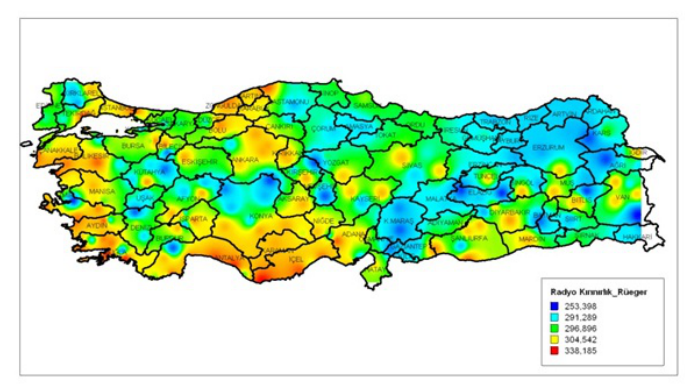

refractivity

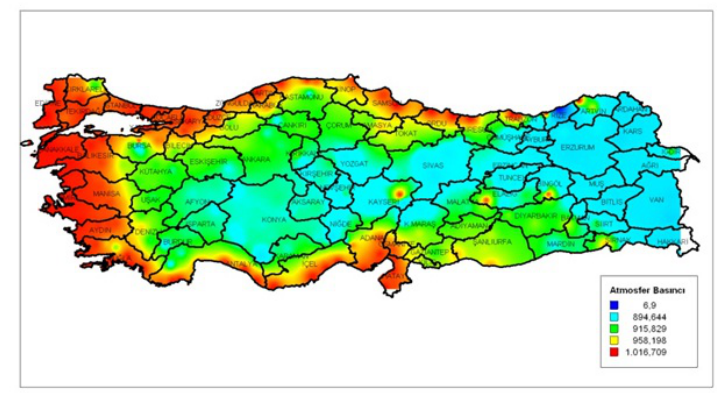

Atmospherical pressure

Figure 2: Measurement stations (top left), maps for evaporation (top right), radio refractivity (bottom left), and atmospherical pressure (bottom right). 


\section{Measurement samples: below $1 \mathrm{GHz}$}

2.8.

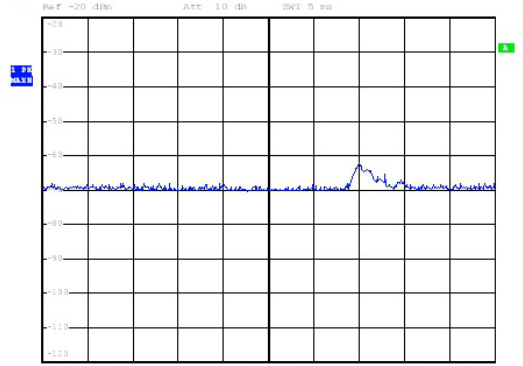

Date: 6. . AvG. $2008 \quad 11: 10: 02$
S

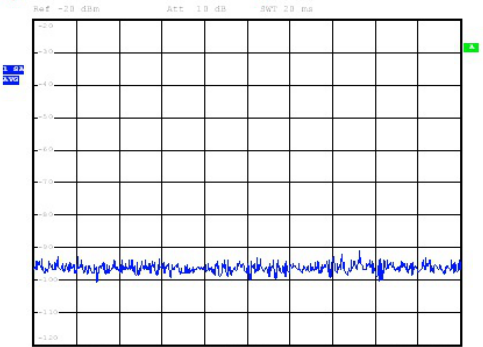

Date: 6.31 . AnG.2008 $\quad 14: 51: 26$
For $90^{\circ}$ polarization $800 \mathrm{MHz}-1 \mathrm{GHz}$
For $180^{\circ}$ polarization $800 \mathrm{MHz}-1 \mathrm{GHz}$

Site: KARAMAN - Yazılı

Figure 3: RFI Polarization Measurement samples (below 1GHz) for the candidate Karaman-Yazılı region. 


\section{Measurement samples: between $1 \mathrm{GHz}$ - 30GHz}

的

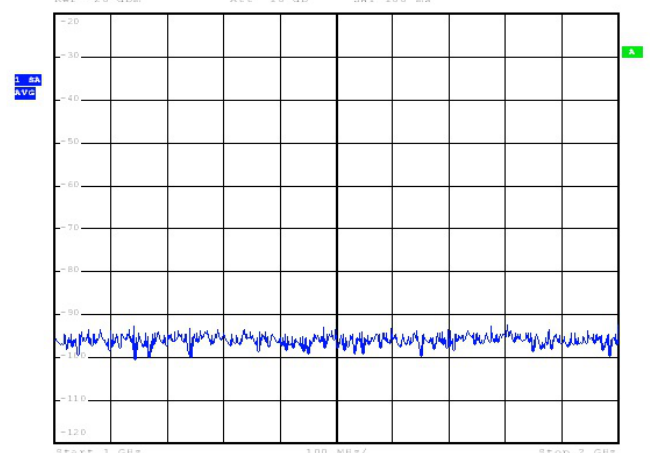

Date: 6. AUG. 2008 13:04:25
的

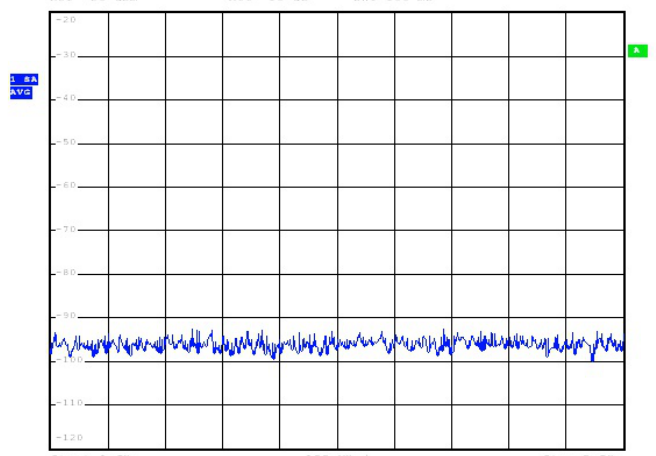

Date: 6. AUG.2008 13:34:29 $90^{\circ}$ polarization $1-2 \mathrm{GHz}$
$45^{0}$ polarization

$1-2 \mathrm{GHz}$

Site: KARAMAN - Yazılı

Figure 4: Measurement samples (between 1-30GHz) for the candidate Karaman-Yazılı region. 


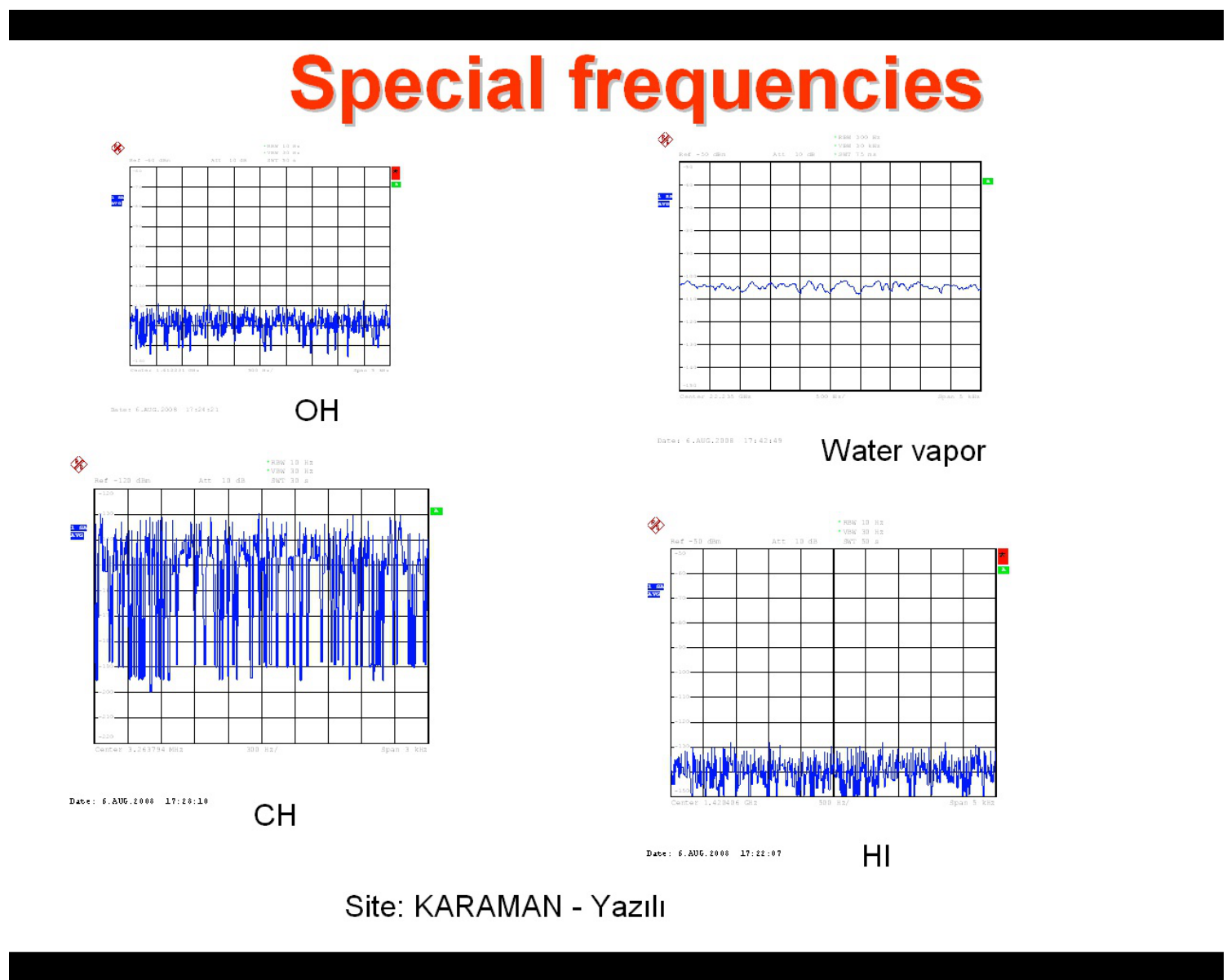

Figure 5: Measurements for $\mathrm{OH}$, Water Vapor, $\mathrm{CH}$ and $\mathrm{HI}$ [1], [2] for the candidate Karaman-Yazılı region. 